\title{
REVIEW
}

\section{HYPOPHOSPHATEMIA IN CRITICALLY ILL CHILDREN}

\author{
Fernanda Souza de Menezes, Heitor Pons Leite, Juliana Fernandez, Silvana Gomes \\ Benzecry and Werther Brunow de Carvalho
}

Menezes FS et al. Hypophosphatemia in critically ill children Rev. Hosp. Clin. Fac. Med. S. Paulo 59(5):306-311, 2004.

The purpose of this paper is to review clinical studies on hypophosphatemia in pediatric intensive care unit patients with a view to verifying prevalence and risk factors associated with this disorder.

We searched the computerized bibliographic databases Medline, Embase, Cochrane Library, and LILACS to identify eligible studies. Search terms included critically ill, pediatric intensive care, trauma, sepsis, infectious diseases, malnutrition, inflammatory response, surgery, starvation, respiratory failure, diuretic, steroid, antiacid therapy, mechanical ventilation. The search period covered those clinical trials published from January 1990 to January 2004. Studies concerning endocrinological disorders, genetic syndromes, rickets, renal diseases, anorexia nervosa, alcohol abuse, and prematurity were not included in this review.

Out of 27 studies retrieved, only 8 involved pediatric patients, and most of these were case reports. One clinical trial and one retrospective study were identified. The prevalence of hypophosphatemia exceeded $50 \%$.

The commonly associated factors in most patients with hypophosphatemia were refeeding syndrome, malnutrition, sepsis, trauma, and diuretic and steroid therapy. Given the high prevalence, clinical manifestations, and multiple risk factors, the early identification of this disorder in critically ill children is crucial for adequate replacement therapy and also to avoid complications.

KEY WORDS: Hypophosphatemia. Children. Malnutrition. Pediatric intensive care unit. Critically ill.

Despite the fact that monitoring of sodium, potassium, and calcium ions is part of the routine of intensive care unit services, little attention has been devoted to phosphorus during the follow-up of critically ill patients. ${ }^{1}$

Required for many biological functions, phosphorus plays an important part in metabolism as a main intracellular anion, enzyme constituent, and component of phosphorylated intermediate compounds, and phosphorus is also a component in cellular membranes, nucleic acids, and nuclear proteins. ${ }^{2,3,4,5}$

Approximately $1000 \mathrm{mg}$ of phosphorus is the recommended daily al- lowance for healthy adults, with an average of $800 \mathrm{mg}$ for normal children., ${ }^{2,67}$ Dietary sources of phosphorus include protein-rich foods, cereals, and nuts. ${ }^{3}$

Phosphorus is absorbed in greater proportions in the jejunum, mainly by passive transport. Excretion takes place essentially by the kidneys, whereby $80 \%$ of the phosphorus is reabsorbed passively within the proxi-

From the Discipline of Nutrition and Metabolism and the Pediatric Intensive Care Unit, Department of Pediatrics, Federal University of São Paulo - São Paulo/SP, Brazil.

E-mail: heitorpl@terra.com.br Received for publication on November 05, 2003. mal tubule, linked with sodium, and regulated by hormonal action and food ingestion. ${ }^{2,3,6}$

Approximately $1 \%$ of the body's total phosphorus reserve is found in the blood, ${ }^{3,8}$ and phosphorus is primarily stored within mineralized tissues (bone and teeth). Phosphorus is also present in soft tissues in the form of phospholipids, phosphoglycides, and phosphoproteins. ${ }^{2,3,6}$

Similar to that of calcium, homeostasis of phosphorus also involves direct participation of the intestine, bones, and kidneys, being maintained by the action of Vitamin D (1.25-dihydroxicolecalciferol), par- 
athyroid hormone (PTH), and calcitonin. Vitamin D acts in the intestine, increasing both calcium and phosphorus absorption. Phosphatemia, however, is practically controlled by renal excretion. PTH secretion, stimulated by a decrease in calcium serum levels, acts in renal reabsorption, reducing urinary excretion of calcium while simultaneously inhibiting the tubular reabsorption of phosphorus. Conversely, when calcium levels are high, calcitonin is released, acting in reverse fashion, i.e. reducing phosphaturia while increasing calcium excretion. ${ }^{9}$

Normal blood concentrations for phosphorus in children aged 5 or under are shown in Table 1. The lower limits are cut-off points for diagnosis of hypophosphatemia. The same classification as for adults is used in children over 5 years old. ${ }^{10}$ It should be noted that given that the range of variation in blood concentrations is wide, serum levels of 3 to $4 \mathrm{mg} / \mathrm{dL}$ in infants generally indicates hypophosphatemia.

Table 1 - Normal blood levels of phosphorus in children under 5 years of age.

\begin{tabular}{ll}
\hline Age Group & Phosphorus $(\mathrm{mg} / \mathrm{dL})$ \\
\hline Newborn & 4.2 to 9.0 \\
1 year & 3.8 to 6.2 \\
2-5 years & 3.5 to 6.8 \\
\hline
\end{tabular}

Source: Worley et al. ${ }^{10}$

In adults, hypophosphatemia is classified as mild (2-2.5 mg/dL), moderate $(1-2 \mathrm{mg} / \mathrm{dL})$, and severe $(<1 \mathrm{mg}$ / $\mathrm{dL}$ ), while normal levels of phosphorus in the blood range between 2.8 and $4.5 \mathrm{mg} / \mathrm{dL}$. ${ }^{6,8}$

In clinical practice, however, the maintenance of normal blood concentrations takes on greater importance in those patients at high risk of developing hypophosphatemia, such as in malnutrition, refeeding, total parenteral nutrition with an absence or inad- equate supply of phosphate, as well as in sepsis, burns, post-operation, and in antiacid, diuretics, and/or steroids use. ${ }^{9}$

The decreasing of the body's stores and increased consumption of phosphorus can explain the onset of hypophosphatemia in malnourished patients. ${ }^{4}$ Besides these factors, endocrine metabolism changes are observed in systemic inflammatory response syndrome (SIRS), along with interleukin production and elevated catabolism, which further contribute toward phosphorus disorders.

In critically ill patients, hypophosphatemia results from chronic phosphate depletion and cellular redistribution. The first mechanism involves situations such as insufficient intake over prolonged periods (malnutrition), reductions in intestinal absorption (antiacid therapy), and increases in urinary losses (diuretic therapy). The redistribution condition, for its part, besides being more frequent in these patients, is commonly responsible for triggering the more severe form of hypophosphatemia. Respiratory alkalosis, high blood concentrations of stress hormones (insulin, glucagon, adrenalin, cortisol), and refeeding syndrome are the main conditions contributing to phosphate redistribution within the organism. ${ }^{5}$

In the majority of cases, the symptoms related to hypophosphatemia are nonspecific, such as fatigue and irritability. $^{2}$ The most important clinical manifestations, such as acute respiratory insufficiency, ${ }^{11,12}$ arrhythmia, ${ }^{13,14}$ hypertension, changes in mental state, and generalized weakness ${ }^{6,15}$ are all generally present in cases of serious hypophosphatemia.

The aim of this study was to carry out a review of the literature on the prevalence, risk factors, and clinical conditions associated with hypophosphatemia in critically ill children.

\section{Selection Criteria}

The following criteria were used to select the included reports:

- Publications stored in the Medline, Embase, and Cochrane Library databases or publications and annals from congresses specializing in intensive pediatric care; published between January 1990 and January 2004;

- Clinical studies and case reports regarding the prevalence and associated risk factors in critically ill patients with hypophosphatemia;

- Participants: patients between 1 month and 18 years of age and of both sexes;

- Variables: prevalence of hypophosphatemia, mortality, length of hospitalization, and associated risk factors;

- Reports that were identified using the following search terms: critically ill, pediatric intensive care, trauma, sepsis, infection diseases, malnutrition, inflammatory response, surgery, starvation, respiratory failure, mechanical ventilation, and diuretic, steroid, and antiacid therapy.

Those studies concerning endocrine disorders, genetic syndromes, rickets, renal diseases, anorexia nervosa, alcohol abuse, and prematurity were excluded.

A total of 27 articles were retrieved; of these, only 8 were related to pediatric age groups, where these comprised 1 prospective clinical study, ${ }^{16} 1$ retrospective, ${ }^{17} 1$ abstract, ${ }^{18}$ and 5 case reports.

The prospective study assessed 238 patients diagnosed with acute infection, where the cut-off point for hypophosphatemia was set at $<4 \mathrm{mg}$ / $\mathrm{dL}$ for minors under 1 year of age and $<3.6 \mathrm{mg} / \mathrm{dL}$ for patients aged between 1 and 14 years. Hypophosphatemia varied according to clinical diagnosis as follows: pneumonia $45 \%$, upper res- 
piratory tract-related bacterial infection $35.7 \%$, urinary tract infection $18 \%$, and viral infection $4.4 \%$. The highest prevalence observed was $61 \%$ in patients with pneumonia and increased C-reactive protein. ${ }^{16}$

Manary et al., ${ }^{17}$ on carrying out a retrospective study on 68 children under 10 years old with kwashiorkor, using $3 \mathrm{mg} / \mathrm{dL}$ as a lower limit for normality, found hypophosphatemia in $76 \%$ of cases. The authors also verified a link between severe hypophosphatemia $(<1 \mathrm{mg} / \mathrm{dL})$ and mortality, reporting a $63 \%$ death rate in patients with severe hypophosphatemia.

The case reports described the onset of hypophosphatemia in malnourished children during refeeding; ${ }^{10,19}$ in adolescents with diagnosed bone tumor, ${ }^{20}$ and severe encephalic cranial trauma. ${ }^{21}$ In another study, authors show a case of hypophosphatemia following intravascular hemolysis secondary to aggressive hyperphosphatemia correction. ${ }^{22}$

In the present review, only $30 \%$ of studies identified were related to the pediatric age group; of these, the majority described isolated cases.

Among the clinical studies, hypophosphatemia was detected in over half of patients assessed. ${ }^{16,17}$ It should be emphasized, however, that these studies differed with regard to the serum level limit of phosphorus required for a diagnosis of hypophosphatemia.

The sole prospective study ${ }^{16}$ identified a $61 \%$ prevalence in patients with a diagnosis of pneumonia and high serum levels of C-reactive protein, demonstrating significant negative correlation between serum levels of phosphate and this acute phase reactant. The results also showed hypophosphatemia to be a transitory condition during the acute phase of infection, stabilizing before $\mathrm{C}$-reactive protein concentration becomes normalized. Despite this, it is important to make clear that the sample did not in- clude critically ill patients, such subjects being more susceptible to the deleterious effects of hypophosphatemia.

The risk factors most often associated with hypophosphatemia were refeeding, ${ }^{10,19}$ malnutrition, ${ }^{10,17}$ infection, ${ }^{16}$ sepsis, ${ }^{4,23,24}$ trauma, ${ }^{21}$ and diuretics $^{9,25}$ and steroids use. ${ }^{5,9}$

Severe hypophosphatemia and its associated complications has been referred to as refeeding syndrome, especially in malnourished patients who have been re-fed rapidly and inappropriately through enteral or parenteral nutrition. In this syndrome, besides phosphorus depletion, changes generally occur in the serum levels of potassium and magnesium, as well in hydric balance, glycose metabolism, and vitamin deficiencies, particularly thia$\min ^{26}$

Refeeding syndrome has received little recognition or study in clinical practice, especially in the pediatric population. Questions remain with regard to this issue, since not all patients undergoing refeeding, even without electrolyte supplements, develop the syndrome. ${ }^{19,26}$ In general, patients at higher risk tend to include those suffering from severe malnutrition, particularly where weight loss exceeds $10 \%$ during a 2 -month period, and lengthy fasting with evidence of stress and depletion is present. ${ }^{27}$ In order to better understand this, it is necessary to know the physiopathological mechanisms of the syndrome, which are described below.

In critically ill, malnourished patients, the serum level of phosphorus prior to refeeding is usually normal. However, as the body's total stores become depleted, there is a risk of developing hypophosphatemia as the supply of nutrients increases cell uptake of phosphorus for synthesis of the phosphorylated compounds (adenosine triphosphate, 2.3-diphosphoglycerate) required for the forming of new tissues..$^{2,3,6,10,19}$ During fasting, a reduction in blood concentrations of insulin takes place; in response to this, glucagon release increases, which then stimulates fat and muscle catabolism to form glycose. Although glyconeogenesis is an important mechanism of adaptation to nutritional deprivation, it contributes to a loss in muscular mass, water, and minerals. Nevertheless, the serum level of phosphorus, along with other depleted ions, is kept at normal levels as a result of adjustments to metabolism. In severe malnutrition, daily phosphorus requirements drop, most likely owing to low ingestion, inhibiting the secretion of parathyroid hormone and stimulating calcitonin release, thereby promoting reductions in renal excretion, increases in intestinal absorption, and bone reabsorption. With the commencement of refeeding, carbohydrates become the main energy source, increasing insulin secretion, which in turn stimulates the uptake of glucose, phosphorus, potassium, magnesium, and water by the cell for anabolism. A combined decrease in the body's stores during fasting, together with increased flow of ions and water to the interior of the cell, promotes the onset of hypophosphatemia, hypocalcemia, hypomagnesemia, and edema, which characterize refeeding syndrome. ${ }^{19,26,27}$

In order to prevent refeeding syndrome, it is recommended that intake of energy, liquids and electrolytes be made gradually, particularly over the first week, during which most complications tend to take place. Adequate volemia and caloric intake should be achieved slowly so as to avoid cardiac overload and rapid electrolyte changes. ${ }^{28,29,30}$ The role of the hospital nutritional therapy team must be emphasized in recognizing and managing patients with refeeding syndrome, to carry out routine monitoring of phosphorus, potassium, and serum levels of magnesium and supplement 
these electrolytes both before and during nutrient intake.

Hypophosphatemia has also been associated with sepsis, which has increased incidence during the first 24 hours of hospitalization. ${ }^{4}$ In systemic inflammatory response syndrome (SIRS), principally secondary to infection, sepsis, or trauma, a release of hormones and interleukins (mediators of hypercatabolism) takes place, which contributes towards hypophosphatemia. However, the mechanisms involved in the genesis of hypophosphatemia during sepsis remain unclear. A number of authors have suggested using serum levels of phosphorus as an early diagnostic marker for sepsis in adults. ${ }^{23,24}$

Patients with severe head trauma are at a high risk of developing hypophosphatemia because of the multiple associated factors that can trigger this disorder, such as respiratory alkalosis and mannitol administration, dextrose solutions, antiacids, and sodium bicarbonate. A study assessing electrolyte disorders in patients admitted with severe head trauma found that $61 \%$ had hypophosphatemia, whereas those patients with mild trauma (control group) had no changes in serum levels of phosphorus. The authors pointed to increased renal losses due to polyuria and cellular redistribution of phosphorus as being possible physiopathological mechanisms to explain hypophosphatemia. $^{1,21}$

Drugs, such as furosemide, used for a prolonged period predispose patients to hypophosphatemia owing to increased urinary excretion of phosphorus $^{9,25}$ as a result of tissue redistribution and reduced intestinal absorption. ${ }^{5,9,31}$

Hypophosphatemia is responsible for numerous deleterious consequences, especially in its severe form, hampering clinical recovery of the patient and being associated with morbidity and potential mortality. ${ }^{2,9}$ The mechanism underlying the majority of complications arising from hypophosphatemia, such as cardiac, respiratory, neuromuscular, and hematological dysfunction, is a deficiency in intermediate compounds such as adenosine triphosphate (ATP) and 2.3-diphosphoglycerate. ${ }^{9,26}$

Hypophosphatemia can trigger a reduction in the contractility of the myocardium, arrhythmias, and cardiomyopathies owing to a fall in the intracellular stores of adenosine triphosphate available for the cardiac muscle. ${ }^{11,26}$ Improvements in cardiac function have been seen following administration of phosphate in surgical patients with hypophosphatemia where presence of sepsis, use of diuretics, and total parenteral nutrition were the main risk factors. ${ }^{25}$

Similarly, the lower availability of ATP for respiratory muscle contraction can explain the onset of acute respiratory insufficiency. ${ }^{26}$ The contractility of the diaphragm appears to be affected in patients with hypophosphatemia and acute respiratory insufficiency on ventilator support, where improved muscular function has been observed after phosphorus reposition, allowing discontinuation of mechanical lung ventilation. ${ }^{11}$ In patients with chronic obstructed pulmonary disease (COPD), hypophosphatemia may represent the central hub of a vicious circle, given its negative effect on respiratory muscle function. Some authors have shown muscular depletion of phosphorus, through biopsies, in approximately half of those patients suffering from respiratory insufficiency due to a COPD diagnosis. ${ }^{12}$

In the context of the hematological system, the decline in levels of 2.3 diphosphoglycerate triggered by hypophosphatemia increases hemoglobin's affinity for oxygen, thereby causing tissue hypoxia and leading to changes in erythrocytes and leukocyte functions, hemolytic anemia, platelet dysfunction, and thrombocytopenia. ${ }^{26}$

The neuromuscular dysfunction associated with hypophosphatemia may also be explained by tissue hypoxia, which leads to alterations in neurological function, irritability, confusion, paralysis, lethargy, paraesthesia, seizure, and coma. ${ }^{2,26}$

Notwithstanding the lack of pediatric studies on hypophosphatemia concerning critically ill patients, and given that the only prospective study has shown the disorder to be transitory, the studies on adults have demonstrated that complications resulting from hypophosphatemia imply poorer clinical outcomes. , $^{211,12,14,26}$ Timely identification and correction of this disorder in patients hospitalized in intensive care units is therefore warranted.

It has been concluded that hypophosphatemia is a metabolic disorder of high prevalence in critically ill patients. The main risk associated factors include refeeding, malnutrition, systemic inflammatory response syndrome, and the use of diuretics and steroids, and the most relevant clinical complications are related to cardiovascular and neuromuscular systems.

Given the significant prevalence found in the pediatric studies analyzed, the frequent presence of risk factors in children in intensive care units, and the potential harmful effects on the clinical outcome of these patients, it is advisable to identify those cases of highest susceptibility for early diagnosis and intervention, thus allowing normal serum levels of phosphorus to be reestablished. 
Menezes FS e col. Hipofosfatemia em crianças gravemente doentes. Rev. Hosp. Clin. Fac. Med. S. Paulo 59(5):306-311, 2004.

Este estudo objetivou realizar revisão da literatura para verificar prevalência, fatores de risco e condições clínicas associadas à hipofosfatemia em crianças gravemente doentes.

Para a pesquisa foram utilizadas as bases de dados Medline, Embase, Cochrane Library, Lilacs abrangendo estudos clínicos publicados de janeiro de 1990 a janeiro de 2004. Os termos utilizados para pesquisa foram: critically ill, pediatric intensive care, trauma, sepsis, infectious diseases, malnutrition, inflammatory response, surgery, starvation, respiratory failure, diuretic, steroid, antiacid therapy, mechanical ventilation. Foram excluídos estudos referentes a distúrbios endócrinos, síndromes genéticas, raquitismo, nefropatias, anorexia nervosa, alcoolismo e prematuridade.

Dos 27 artigos inicialmente identificados, 8 referiam-se à faixa etária pediátrica, sendo a maioria deles relatos de casos isolados. Nos estudos clínicos selecionados, a prevalência de hipofosfatemia foi superior a $50 \%$.

Os principais fatores associados à hipofosfatemia foram realimentação, desnutrição, sepse, trauma, uso de diuréticos e corticoesteróides. Considerando-se a elevada prevalência, as repercussões clínicas e os múltiplos fatores de risco para hipofosfatemia em crianças internadas em unidade de cuidados intensivos, a identificação precoce de pacientes suscetíveis a esse distúrbio é essencial para o tratamento oportuno e prevenção de complicações.

UNITERMOS: Hipofosfatemia. Crianças. Desnutrição. Unidade de Terapia Intensiva Pediátrica. Gravemente doente.

\section{REFERENCES}

1. Polderman KH, Bloemers FW, Peerdeman SM, Girbes AR. Hypomagnesemia and hypophosphatemia at admission in patients with severe head injury. Crit Car Med 2000;28(6):2022-5.

2. Miller DW, Slovis CM. Hypophosphatemia in the emergency department therapeutics. Am J Emerg Med 2000;18:457-61.

3. Crook MA, Hally V, Panteli JV. The importance of the refeeding syndrome. Nutrition 2001;17:632-7.

4. Bollaert PE, Levy B, Nace L, Laterre PF, Larcan A. Hemodynamic and metabolic effects of rapid correction of hypophosphatemia in patients with septic shock. Chest 1995;107(6):1698-1701.

5. Thomas C, Fourrier F. Hypophosphorémies em réanimation. Réanimation 2003;12:280-7.

6. Weisinger JR, Bellorín-Font E. Magnesium and phosphorus. Lancet 1998;352(1):391-6.

7. National Research Council - Recommended Dietary Allowances. National Academy of Science. 10 $0^{\text {th }}$ ed. Washington, DC, 1989.

8. Rosen GH, Boullata JI, O'Rangers EA, Enow NB, Shin B. Intravenous phosphate repletion regimen for critically ill patients with moderate hypophosphatemia. Crit Care Med $1995 ; 23(7): 1204-10$.

9. Subramanian R, Khardori R. Severe hypophosphatemia. Pathophysiologic implications, clinical presentations and treatment. Medicine 2000;79(1):1-8.

10. Worley G, Claerhout SJ, Combs SP. Hypophosphatemia in malnourished children during refeeding. Clin Pediatr 1998;37:347-52.
11. Aubier M, Murciano D, Lecocguic Y, Viires N, Jacquens Y, Squara $\mathrm{P}$, et al. Effect of hypophosphatemia on diaphragmatic contractility in patients with acute respiratory failure. N Engl J Med 1985;313:420-4.

12. Fiaccadori E, Coffrini E, Fracchia C, Rampulla C, Montagna T, Borghetti A. Hypophosphatemia and phosphorus depletion in respiratory and peripheral muscles of patients with respiratory failure due to COPD. Chest 1994;105(5):1392-8.

13. Schwartz A, Gurman G, Cohen G, Gilutz H, Brill S, Schily M, et al. Association between hypophosphatemia and cardiac arrhythmias in the early stages of sepsis. Eur J Intern Med 2002;13(7):434-48.

14. Ognibene A, Ciniglio R, Greifenstein A, Jarjoura D, Cugino A, Blend D, et al. Ventricular tachycardia in acute myocardial infarction: the role of hypophosphatemia. South Med J 1994;87(1):65-9

15. Bugg NC, Jones JA. Hypophosphatemia pathophysiology, effects and management on the intensive care unit. Anaesthesia 1998;53(9):895-902.

16. Antachopoulos C, Margeli A, Giannaki M et al. Transient hypophosphataemia associated with acute infectious disease in paediatric patients. Scand J Infect Dis 2002;34:836-9.

17. Manary MJ, Hart CA, Whyte MP. Severe hypophosphatemia in children with kwashiorkor is associated with increased mortality. J Pediatr 1998;133(6):789-91.

18. Pedreira P, Lima LFP, Menezes FS et al. High prevalence of hypophosphatemia in critically ill infants (abstract). Ped Crit Care Med 2003;4(3):MP90. 
19. Afzal NA, Addai S, Fagbemi A et al. Refeeding syndrome with enteral nutrition in children: a case report, literature review and clinical guidelines. Clin Nutr 2002;21(6):515-20.

20. Paterson CR, Naismith KI, Young AJ. Severe unexplained hypophosphatemia. Clin Chem 1992;38(1):104-7.

21. Helms O, Freys G, Pottecher T. Severe hypophosphatemia and grave head trauma. Ann Fr Anesth Reanim 2002;21(6):525-9.

22. Melvin JD, Watts RG. Severe hypophosphatemia: a rare cause of intravascular hemolysis. Am J Hematol 2002;69(3):223-4.

23. Landenberg Pv, Shoenfeld Y - New approaches in the diagnosis of sepsis. IMAJ 2001;3:439-42.

24. Barak V, Schwartz A, Kalickman I, Nisman B, Gurman G, Shoenfeld Y. Prevalence of hypophosphatemia in sepsis and infection: the role of cytokines. Am J Med 1998;104:40-7.

25. Zazzo JF, Troche G, Ruel P, Maintenant J. High incidence of hypophosphatemia in surgical intensive care patients: efficacy of phosphorus therapy on myocardial function. Intensive Care Med 1995; 21:826-31.
26. Solomon SM, Kirby DF. The Refeeding Syndrome: A Review. JPEN 1990;14(1):90-7.

27. Crook MA, Hally V, Panteli JV. The importance of the refeeding syndrome. Nutrition 2001;17:632-7.

28. Faintuch J, Soriano FG, Ladeira JP, Janiszewski M, Velasco IT, Gama-Rodrigues JJ. Refeeding procedures after 43 days of total fasting. Nutrition 2001;17:100-4.

29. Shadaba A, Paine J, Adlard R, Dilkes M. Re-feeding syndrome. J Laryngol Otol 2001;115:755-6.

30. Mallet M - Refeeding Syndrome. Age Ageing 2002;31:65-6.

31. Haglin L, Burman LA, Nilsson M. High Prevalence of hypophosphatemia amongst patients with infectious diseases. A retrospective study. J Intern Med 1999;246(1):45-52. 